\title{
Social values and conformity
}

\author{
Nancy E. Hawkins ${ }^{2}$ and Mèrle E. Meyer \\ WHITMAN COLLEGE
}

\begin{abstract}
To test the hypothesis that group pressure has some immediate and lasting effects on the value of an individual, 61 Ss were chosen according to their social value scores on the Allport-Vernon-Lindzey "Study of Values" scale, 33 having high social values and 28 having low ones. Half the Ss from each extreme were used as a control group, the other half was then placed in a social pressure situation in which the social values of the "group" appeared to be opposite from those of the individual subject. A written retest was used later to measure the amount of conversion. The results were found to be in the direction of the hypothesis.
\end{abstract}

\section{Problem}

A number of investigations of conformity (e.g. Sherif, 1935; Asch, 1955; Crutchfield, 1955; Bass, 1961) have suggested some of the conditions under which individuals were likely to conform to group pressure with respect to specific stimulus situations. However, Blake \& Mouton (1961) point out that too often the stimuli used in conformity studies such as judgment of lengths of lines, the autokinetic effect, counting of metronome clicks, and solving arithmetic problems, have little applicability to conformity situations in everyday life. Consequently, they felt that there was a need for experimentation with more personally significant situations as well as a need to study the long range effects of group pressure on an indiyidual.

This study dealt with some of the weaknesses of previous studies. It investigated the effects of group pressure on an individual's social values, not only does it measure conformity to group attitudes in the experimental situation, but it also measures conformity to these attitudes at a later time to test for any " conversion" effects. The prediction was that the social values of the individual as measured during the group pressure situation would be significantly different from the individual's social values as tested before the group pressure. Furthermore, there would be some "conversion" effects of the group pressure on social values, but that these would be of lesser degree than the direct changes observed during the pressure situation.

\section{Subjects}

The Ss were taken from the 207 freshman students of Whitman College who had taken the Allport-VernonLindzey "Study of Values" (1960). The sample consisted of $61 \mathrm{Ss}$ : 15 males and 18 females who scored at the upper extreme on the social scale of the test, and 14 males and 14 females whose scores fell at the lower extreme. Each set of males and females were randomly divided into the experimental and control groups.

\section{Procedure}

The Ss in both groups were given written forms of Part 1 of the Allport-Vernon-Lindzey "Study of Values" questionnaire with a choice of two possible answers for each question. A few weeks later, members of the experimental group came in groups of four for the group situation. The four were either all low scorers or all high scorers on the Social scale of the previous test. The Ss were seated at one side of a long table, on both sides of the E, with plywood panels separating them from one another. At the center of the table was a projector and a hidden control panel operated by E. Directly in front of each $\mathrm{S}$ was a panel of eight lights (two columns and four rows) and a pair of response buttons. At the front of the room was a screen visible to all Ss.

The Ss were told that items from the "Study of Values", which they had previously taken, would be shown on the screen. Each of them was to choose an answer to each item as it appeared; then as his number was called, he was to respond by pressing either button $a$ or button $b$, whichever one corresponded to his answer. It was indicated that as each $\mathrm{S}$ responded, the light representing his answer would be illuminated on all the panels, thus giving the Ss feedback on the answers of their compatriots. A short demonstration was given to insure that everyone understood the instructions. While the Ss were led to believe that their panels of lights indicated the response of each of the other Ss, actually each $\mathrm{S}$ was in the same situation (each was subject four) and each panel of lights was controlled by $E$. Thus $E$ was the only person aware of the actual responses of the four Ss.

Thirty statements were used, 10 items pertaining to social values and 20 items not pertaining to social values. One week after the group pressure situation, the Ss in both control and experimental groups were given a written retest in order to determine whether or not any conversion effect had taken place among the experimental Ss.

\section{Results and Diseussion}

For each $\mathrm{S}$ in the experimental group the difference between the social value score obtained on the written pre-test and comparable score from the pressure situation was computed. These differences were then summed and means computed. A similar procedure was employed to find the difference scores and means between the pre- and post-test of the control Ss. The experimental and control groups were then compared.

The results indicate that there was a significant difference between the experimental and the control groups in the conformity situation with low social values 
$(t=2.65 ; \mathrm{df}, 26 ; p=.007)$, as well as for the conformity situation with high social values $(t=2.14 ; \mathrm{df}, 31$; $\mathrm{p}=.022$ ). Combining the high and low social values and comparing the experimental and control groups, a significant difference was observed between men $(t=2.72$; $\mathrm{df}, 27 ; \mathrm{p}=.006)$ and women $(\mathrm{t}=2.11 ; \mathrm{df}, 30 ; \mathrm{p}=.0 \div 3)$. From these findings it is suggestive that individuals conform to situations which are of personal significance such as their value system.

To test for the significance of the amount of conversion over time, the difference between the social value score on the pre-test and the comparable score on the posttest was computed for each $\mathrm{S}$ in the experimental and control groups.

A significant difference between the experimental and control groups in the conversion situation occurred only with the low social group $(t=2.13 ; d f, 26 ; p=.023)$. The difference for the high social values group was not significant $(t=.905 ; \mathrm{df}, 31 ; \mathrm{p}=.190)$. When the high and low social values were combined and the experimental and control groups were compared non-significant differences were obtained between men $(t=1.592 ; \mathrm{df}, 27$; $p=.075)$ and women $(t=1.261 ; d f, 30 ; p=.120)$.
Even though in the conversion situation limited t's were significant, it may be noted that the other p's were fairly low. It may be hypothesized that group pressure may have some effect over time upon the social values, although the effect is much less than that obtained at the time of the pressure situation itself.

\section{References}

ALLPORT, G. W., VERNON, P. E., \& LINDZEY, G. Study of Values. Boston: Houghton Mifflin Company, 1960.

ASCH, S. E. Opinions and social pressure. Scient. American, Nov., 1955.

BASS, B. M. Conformity, deviation, and a general theory of interpersonal behavior. In I. A. Berg \& B. M. Bass (Ed.), Conformity and deviation. New York: Harper, 1961. Pp. 38-100.

BLAKE, R., \& MOUTON, J. S. Conformity, resistance, and conversion. In I. A. Berg \& B. M. Bass (Ed.), Conformity and deviation. New York: Harper, 1961. Pp. 1-37.

CRUTCHFIELD, R. Correlates of individual behavior in a controlled group situation. Amer. Psychologist, 1955, 10, 191-198.

SHERIF, M. A study of some social factors in perception. Arch. Psychol., 1935, 27, No. 187.

\section{Notes}

1. This article is in part based upon a thesis submitted by the senior author to the faculty of Witman College in partial fulfillment of the requirements for Honors in Psychology.

2. For reprints, write the first author, now at the Department of Psychology, University of Oregon, Eugene, Ore. 